\title{
ATENDIMENTO ÀS NECESSIDADES SOCIOEMOCIONAIS DE ESTUDANTES COM DUPLA EXCEPCIONALIDADE: REVISÃO INTEGRATIVA DA LITERATURA INTERNACIONAL
}

\author{
Josilene Domingues Santos Pereira* \\ Rosemeire de Araújo Rangni**
}

\begin{abstract}
RESUMO: Estudos sobre a dupla excepcionalidade têm aumentado na literatura da educação de dotados e talentosos. Estudantes duplamente excepcionais (2E) demonstram capacidades elevadas em uma ou mais áreas associadas a uma deficiência ou transtorno/distúrbio ou síndrome e necessitam de intervenções socioemocionais e acadêmicas que atendam as duas excepcionalidades. O objetivo deste artigo é apresentar as práticas de atendimento, no âmbito socioemocional, para esse público ao realizar uma revisão integrativa da literatura internacional, publicada de 2018 a 2020. Foram encontrados treze artigos $(\mathrm{N}=13)$. Desse total, apenas quatro $(\mathrm{N}=4)$ foram resultados de pesquisas empíricas. Os resultados apontaram que: (i) os estudantes $2 \mathrm{E}$ necessitam de diversos apoios, na escola e na família, visando ao desenvolvimento cognitivo, social e emocional; (ii) há poucas evidências empíricas sobre intervenções específicas para esse público; (iii) as intervenções, no âmbito socioemocional, são necessárias não só para o bem-estar socioemocional dos estudantes $2 \mathrm{E}$ como também para a melhoria do desempenho acadêmico; (iv) as intervenções efetivas devem ser focadas nos talentos e nos potenciais e, ao mesmo tempo, oferecer apoio para as necessidades acadêmicas e socioemocionais. Conclui-se que são necessárias pesquisas empíricas com intervenção que possam estabelecer relações causais entre as estratégias e os resultados para o desenvolvimento socioemocional desses estudantes.
\end{abstract}

PALAVRAS-CHAVE: Dotação e talento; Dupla excepcionalidade; Estudantes duplamente excepcionais (2E); Intervenção.

\section{SUPPORTING SOCIAL-EMOTIONAL NEEDS OF TWICE-EXCEPTIONAL STUDENTS: INTEGRATIVE REVIEW OF INTERNATIONAL LITERATURE}

\begin{abstract}
Studies on twice exceptionality have grown in the literature on the education of the gifted and talented. Twice- exceptional students (2E) demonstrates high abilities in one or more areas associated with a disability and need socio-emotional and academic interventions that address both exceptionalities. The aim of this integrative review of the international literature, published from 2018 to 2020, was to identify care practices, specifically, in the socio-emotional sphere, for this audience. Thirteen articles were found $(\mathrm{N}=13)$. Of this total, only four $(\mathrm{N}=4)$ were results of empirical research. The results showed that (i) $2 \mathrm{E}$ students need different support, at school and in the family, aiming at cognitive, social and emotional development. (ii) There is little empirical evidence on specific interventions for this audience. (iii) Interventions, in the socio-emotional sphere, are necessary not only for the socio-emotional well-being of $2 \mathrm{E}$ students but also for the improvement of academic performance. (iv) Effective interventions must focus on talent and potential while providing support for academic and socioemotional needs. It is possible to conclude that empirical and intervention research is needed that can establish causal relationships between strategies and outcomes in the socio-emotional and academic development of $2 \mathrm{E}$ students.
\end{abstract}

KEYWORDS: Giftedness and talent; Twice-exceptionality; twice-exceptional (2E) students; intervention.

\footnotetext{
* Doutoranda em Educação Especial pelo Programa de Pós-Graduação da Universidade Federal de São Carlos (UFSCar). Professora Adjunta do Instituto Federal da Bahia (IFBA), campus Vitória da Conquista. Membro do Grupo de Pesquisa para o Desenvolvimento do Potencial Humano (GRUPOH). Orcid: https://orcid.org/0000-0001-5392-9006. E-mail: josilenesantos@ifba.edu.br

** Doutora em Educação Especial. Professora Associada I do Departamento de Psicologia e do Programa de Pós-Graduação em Educação Especial pela Universidade Federal de São Carlos (UFSCar). Líder do Grupo de Pesquisa para o Desenvolvimento do Potencial Humano (GRUPOH). Orcid: http://orcid.org/0000-0002-8752-9745. E-mail: rose.rangni@ufscar.br
}

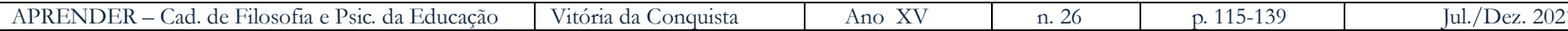




\section{Introdução}

Há mais de cinquenta anos, estudiosos da área de altas habilidades ou superdotação ${ }^{1}$ têm se debruçando sobre um fenômeno que ficou conhecido como dupla excepcionalidade entre a população especial de indivíduos dotados e talentosos (BALDWING et al., 2015). Apesar da existência na literatura de estudos que relatavam a presença de capacidades elevadas associadas a dificuldades de leitura, escrita e aritmética em crianças desde 1923, com o trabalho pioneiro da psicóloga e educadora Leta Hollingworth, foi somente, nas últimas três décadas, no mundo todo, que essa população especial de estudantes dotados e talentosos começou a chamar a atenção de estudiosos, de profissionais da educação, da saúde e de familiares (BAUM; SHADER, 2020; BAUM; SHADER; OWEN, 2017; KAUFMAN, 2018).

Em 2014, no National Twice-Exceptional Community of Practice (2ECoP), os estudiosos sintetizaram os conhecimentos acumulados sobre essa população especial de estudantes dotados e talentosos e formularam uma definição dessa condição para ser compartilhada entre todos os interessados pela temática (pais, educadores, profissionais da saúde, estudiosos). Esse trabalho em cooperação tinha como intuito permitir um avanço nos estudos sobre a dupla excepcionalidade e uma compreensão mais coesa sobre esse fenômeno (BALDWING et al., 2015; BAUM; SHADER; OWEN, 2017; KAUFMAN, 2018; REIS; BAUM; BURKE, 2014). A partir desse encontro, reconheceu-se que os estudantes duplamente excepcionais

[...] evidenciam uma elevada capacidade em uma área ou mais e, ao mesmo tempo, uma deficiência ou transtorno/distúrbio ou síndrome, que resulta em um conjunto único de características. A capacidade elevada pode se destacar, escondendo uma deficiência ou um transtorno/distúrbio ou uma síndrome ou, ao contrário, quando uma deficiência ou um transtorno/distúrbio ou uma síndrome pode esconder o potencial elevado. É possível também que cada uma das excepcionalidades pode mascarar a outra, de modo que nenhuma das duas é reconhecida ou atendida. Estudantes duplamente excepcionais podem apresentar um desempenho abaixo, na média ou acima da média de sua série escolar [...] (BALDWING et al., 2015, p. 212, tradução nossa).

Além disso, esperava-se que esse trabalho cooperativo pudesse também auxiliar na promoção de políticas educacionais específicas para esse público, na oferta de cursos de formação de professores e ainda no estabelecimento de parâmetros para a seleção e a participação dos estudantes duplamente

\footnotetext{
1 Termo utilizado na Lei de Diretrizes e Bases da Educação Nacional (BRASIL, 1996). No entanto, doravante, neste artigo, adota-se, nas citações diretas e indiretas de pesquisadores internacionais, a tradução exata das terminologias originais utilizadas nos textos, como dotação/dotado para giftedness/gifted e talento/talentoso para Talent/talented. Por dotação, deve-se compreender a competência acima da média em um ou mais domínios de capacidade; e por talento, o desempenho acima da média em um ou mais campos do desempenho humano (GAGNÉ, 1985).
} 
excepcionais (2E) em programas educacionais direcionados para a duplicidade de necessidades educacionais (LEE; RITCHOTTE, 2018).

Baum, Shader e Owen (2017) asseveram ainda que o cruzamento entre as capacidades elevadas e a presença de um transtorno/distúrbio ou uma deficiência ou uma síndrome constitui um amálgama paradoxal de comportamentos e características que serão indicados por uma flutuação comportamental na qual o indivíduo ora apresenta indicativos de dotação e talento ora demonstra suas dificuldades comportamentais, acadêmicas e socioemocionais.

Esses autores também salientam que os estudantes $2 \mathrm{E}$ apresentam um perfil único, muitas vezes, conflitante, e não estático de características que se movimentam em diferentes momentos, em variadas circunstâncias, e em reposta à mudança das condições socioambientais. Por isso, no contexto educativo, entender o que ocorre quando se trabalha com a combinação de duas excepcionalidades é crucial para encontrar as necessidades emocionais e educacionais de estudantes 2E (BAUM; SHADER; OWEN, 2017; TRAIL, 2011).

Dados de prevalência dessa população de estudantes não foram ainda catalogados, mas os profissionais da área estimam um percentual de 5\% a 6\% de crianças com deficiência ou com um transtorno/distúrbio ou com uma síndrome possam ser dotados e talentosos (LEE; RITCHOTTE, 2018). Os estudantes 2E são, comumente, agrupados em três grupos (BALDWING et al., 2015; BAUM; SHADER; OWEN, 2017):

a) Os estudantes são identificados apenas como dotados e talentosos sem qualquer avaliação que indique um transtorno/distúrbio, uma deficiência ou uma síndrome. Neste grupo, as dificuldades dos estudantes não são percebidas porque eles utilizam estratégias compensatórias. Desse modo, devido às elevadas capacidades, conseguem mascará-las. Com o passar do tempo, começa a ocorrer uma discrepância considerável entre o potencial e o desempenho desses estudantes, que passam a apresentar baixo rendimento na escola, baixo autoconceito e falta de motivação.

b) Os estudantes são encaminhados para os serviços da Educação Especial por conta de uma deficiência, um transtorno/distúrbio ou síndrome e não são reconhecidos pelos seus potenciais. Nesse grupo, os estudantes frequentemente demonstram um baixo rendimento em duas ou mais matérias e/ou manifestam comportamentos inadequados, que comprometem a manifestação de suas capacidades elevadas. Esses estudantes $2 \mathrm{E}$ são notados por aquilo que não conseguem fazer e não por aquilo que são capazes de fazer nas áreas de interesses. Quando a escola enxerga apenas dificuldades devido à presença de uma deficiência ou um transtorno/distúrbio ou uma síndrome e oferece serviços educacionais especiais por conta disso, pode promover, nesses estudantes, experiências e sentimentos genuínos de inadequação.

c) Os estudantes desse grupo não são identificados nem pela dotação nem pelo talento e tampouco pela presença de uma deficiência ou de um transtorno/distúrbio ou de uma síndrome. Cada excepcionalidade mascara a outra de modo recíproco. Em razão disso, esses estudantes não têm 
participado de qualquer serviço educacional especializado. De acordo com Baum, Shader e Owen (2017), os estudantes desse grupo são os mais difíceis de serem identificados, pois passam despercebidos pela escola. Por essa razão, defendem a necessidade da escola propor práticas educativas mais criativas, como debates, apresentações teatrais, projetos extracurriculares dentre outras, pois o talento pode emergir nesses momentos.

Em uma revisão minuciosa da literatura empírica que cobriu vinte anos de pesquisa, Foley-Nicpon et al. (2011) reconheceram que os estudantes 2E possuem características cognitivas, emocionais e sociais específicas que se diferem tanto daqueles estudantes com apenas dotação e talento quanto daqueles que possuem somente uma deficiência ou um transtorno/distúrbio ou uma síndrome. No Quadro 1, podese visualizar uma síntese dos traços mais comuns que revelam o amálgama conflitante entre os traços mais destacados e as dificuldades desses estudantes.

Quadro 1- Síntese de características mais comuns de estudantes duplamente excepcionais

\begin{tabular}{|c|c|}
\hline Traços mais destacados/pontos fortes & Dificuldades \\
\hline $\begin{array}{ll}\text { - } & \text { vocabulário avançado } \\
\text { - } & \text { criatividade } \\
\text { - } & \text { cugenhosidade } \\
\text { - } & \text { inventividade } \\
\text { - } & \text { questionador(a) } \\
\text { - } & \text { capacidade para resolução de problemas } \\
\text { - } & \text { sofisticado senso de humor } \\
\text { - } & \text { ampla gama de interesses } \\
\text { - } & \text { ideias e opiniões avançadas } \\
\text { - } & \text { talento especial ou um interesse específico de } \\
& \text { estudo }\end{array}$ & $\begin{array}{l}\text { - } \text { sentimento de frustração constante } \\
\text { - } \text { teimosia } \\
\text { - } \text { manipulação } \\
\text { - } \text { oposicionistas, argumentativos } \\
\text { - desibilidade à crítica } \\
\text { - dificuldade com a expressão escrita } \\
\text { - } \quad \text { falta de organização e de habilidades de } \\
\text { - } \quad \text { dificudo } \\
\end{array}$ \\
\hline
\end{tabular}

Fonte: Trail (2011, p. 3, tradução nossa).

Além disso, outro traço comum de estudantes $2 \mathrm{E}$ é a assincronia acentuada no desenvolvimento, que se manifesta por uma desigualdade no desenvolvimento de suas habilidades físicas, emocionais, sociais e intelectuais, isto é, o desenvolvimento intelectual pode ser muito além do dos colegas de mesma faixa etária, ao passo que o desenvolvimento físico e socioemocional ficam muito aquém da idade cronológica (BAUM; SHADER, 2020; COLEMAN; GALLAGHER, 2015; LOVECKY, 2004; WEBB et al., 2016). Esse padrão desenvolvimental assincrônico dos estudantes $2 \mathrm{E}$ tem revelado também que eles tendem a ter mais problemas sociais e emocionais do que os estudantes identificados apenas como dotados e talentosos, sendo necessárias intervenções adicionais, tais como terapia psicológica e outros serviços de saúde mental (FOLEY-NICPON; ASSOULINE, 2015; FOLEY-NICPON, 2016).

Os estudantes 2E, diariamente, enfrentam dificuldades, tanto na escola quanto na vida, principalmente devido ao cruzamento paradoxal das duas excepcionalidades que os levam ainda a sentirem frequentes frustrações emocionais (KING, 2005). Vários autores (KING, 2005; RITCHOTTE; ZAGHLAWAN, 2019; TRAIL, 2011) afirmam que essa população de estudantes dotados e talentosos 
sente extremamente frustrada quando não consegue alcançar resultados condizentes com suas próprias expectativas e com as expectativas de outras pessoas, como, por exemplo, os professores, os quais não entendem o porquê de um estudante tão capaz não conseguir apresentar um desempenho correspondente com a sua capacidade.

Vale frisar ainda que, por conta desse cruzamento paradoxal de características entre o potencial e as dificuldades acadêmicas, muitos estudantes $2 \mathrm{E}$ podem desenvolver baixo autoconceito, ansiedade, demonstram mais insatisfação pessoal, sentimento de inadequação em relação aos colegas de classe e percepção de isolamento social (KING, 2005), baixa autoestima, baixa autoeficácia e dificuldade de relacionar com os colegas de classe, pobres habilidades sociais e/ou comportamento antissocial (BAUM; SHADER; OWEN, 2017; TRAIL, 2011).

Considerando essa singularidade no perfil de carcaterísticas dos estudantes $2 \mathrm{E}$, vários estudiosos (BALDWING et al., 2015; BAUM; SHADER; HÉBERT, 2014; BAUM; SHADER; OWEN, 2017; COLEMAN; GALLAGHER, 2015; FOLEY-NICPON et al., 2011; FOLEY-NICPON, 2016; OWENS et al., 2016; REIS; BAUM; BURKE, 2014; TRAIL, 2011) têm defendido a oferta de serviços educacionais que atendam, de modo simultâneo, as duas excepcionalidades: programas de desenvolvimento do talento e atendimentos educacionais especializados para intervenção/remediação nas dificuldades na aprendizagem, nas funções executivas, nas habilidades sociais e nos problemas emocionais.

É necessário reconhecer, no entanto, como expõe Baum (2004), que, infelizmente, o aumento da atenção em relação a essa população especial de estudantes dotados e talentosos, no campo das investigações científicas, ainda não vem apresentando o sucesso esperado no que diz respeito à oferta de programas educacionais que sejam capazes de atender os estudantes $2 \mathrm{E}$. De fato, em dezenove anos de pesquisas, Amran e Majid (2019) encontraram apenas quarenta e quatro $(\mathrm{N}=44)$ artigos que tratavam de intervenções para esse público, o que corresponde a uma média de, aproximadamente, dois estudos publicados por ano.

Nessa revisão sistemática de artigos publicados de 2000 a 2018, Amran e Majid (2019) identificaram cinco categorias usadas nas investigações sobre intervenções para estudantes 2E: estratégias de aprendizagem/ acadêmicas; a concepção teórica deve ser baseada no talento e nos interesses dos estudantes; estratégias de intervenção nas dificuldades; estratégias focadas em arte/música e em utilização de tecnologia assistiva ${ }^{2}$. Chegaram à conclusão de que uma intervenção efetiva deve ser adaptada tanto para favorecer as áreas de talento de cada estudante quanto fornecer serviços de remediação e apoio para as necessidades emocionais e sociais.

\footnotetext{
2 Segundo Amran e Majid (2019), apesar de limitados estudos, existe uma variedade de tecnologia assistiva disponível atualmente que fornece excelentes oportunidades de aprendizagem para estudantes $2 \mathrm{E}$, pois pode ser usada para promover modificações e adaptações curriculares e ainda oportunidades para aprofundar os conhecimentos nas áreas de interesse do estudante. De acordo com esses autores, os estudos que utilizaram a tecnologia assistiva para esse grupo de estudantes revelaram que houve mais interesse em aprofundar os conhecimentos, mais situações de aprendizagem em ambiente experimental, ajudando-os a expressarem sua criatividade, o pensamento crítico.
} 
Apesar de ser uma revisão ampla, com recorte temporal de dezenove anos, Amran e Majid (2019) não incluíram estudos teóricos e nem focalizaram as intervenções socioemocionais. Com o objetivo de mapear as práticas de atendimento, no âmbito socioemocional, para esse público ao realizar uma revisão integrativa da literatura internacional, publicada de 2018 a 2020 para os estudantes 2E, esta revisão integrativa, busca responder às seguintes questões:

1) Como se caracterizam as investigações sobre intervenção para os estudantes $2 \mathrm{E}$ publicadas de 2018 a 2020? Quantos artigos teóricos, empíricos ou de revisão foram selecionados nesta revisão integrativa? Como se classificam as evidências sobre as práticas/estratégias de atendimento para os estudantes 2E? Quem são os participantes nos estudos empíricos? Quais os temas abordados nos artigos?

2) Quais as abordagens que embasam as práticas de atendimento para esses estudantes?

3) Quais as práticas de atendimento para atender às necessidades emocionais e sociais de estudantes $2 \mathrm{E}$ ?

Identificar as práticas de atendimento que têm sido utilizadas nas pesquisas é particularmente significativo para que pais e professores possam ofertar aos filhos e aos alunos as intervenções mais adequadas às necessidades socioemocionais e acadêmicas de estudantes 2E. Conforme assinalam Leurox e Levitt-Perlman (2000), as intervenções são fundamentalmente importantes para que esses alunos possam se tornar pessoas independentes e membros valiosos para a sociedade.

\section{Método}

Para responder às questões de pesquisa, utilizou-se como procedimento metodológico a Revisão Integrativa da Literatura. Esse tipo de revisão, inicialmente utilizada na área da saúde, tem como objetivo proporcionar "uma síntese do conhecimento e a incorporação da aplicabilidade de resultados de estudos significativos na prática” (SOUZA; SILVA; CARVALHO, 2010, p. 102).

Este método de revisão distingue-se tanto da Revisão Narrativa, porque parte de uma questão específica e bem delimitada, por meio de um processo sistemático de busca, coleta e análise de dados (CORDEIRO et al.; 2007), quanto da Revisão Sistemática, porque permite a inclusão de literatura com diversos delineamentos metodológicos - experimentais ou não-experimentais, teóricos, revisões -, com o objetivo de fornecer informações mais amplas sobre um assunto ou um problema de pesquisa (WHITTEMORE; KNAFL, 2005). 


\section{Critérios para seleção e análise dos dados}

A busca foi realizada em duas bases eletrônicas, o portal de Periódicos CAPES (https://wnwperiodicos-capes-gov-br.ęl.periodicos.capes.gov.br/)e a Sage Journal (bttps://journals.sagepub.com/). A primeira base possibilita o acesso à produção científica mundial atualizada e agrega mais de 50.000 títulos de periódicos nacionais e internacionais, incluindo artigos, teses, livros, patentes dentre outros. A Sage Journal é uma base de dados composta por diversos periódicos com concentração nas áreas de Ciências Sociais Aplicadas e Ciências Humanas.

A busca foi realizada nos meses de maio e junho de 2021. O mesmo processo de coleta de dados foi aplicado nas duas bases. Utilizou-se a busca avançada por meio dos operadores booleanos $A N D$ e OR e as seguintes palavras-chave: twice-excepctional, gifted disabled, intervention e supporting e o recorte temporal de 2018 a 2020. A estratégia de combinação das palavras-chave e os resultados da busca podem ser visualizados no Quadro 1.

Foram selecionados artigos que preencheram os seguintes critérios de inclusão: a) periódico revisado por pares; b) idioma inglês; c) disponibilidade integral do texto e d) ênfase em práticas de atendimento ou instruções nas áreas comportamental, socioemocional e/ou educacional em ambientes escolares, clínicos e familiares para estudantes $2 \mathrm{E}$. Visando ao refinamento da seleção, também foram utilizados critérios de exclusão: a) não abordam o tema; b) artigos não disponibilizados na íntegra; c) duplicidade de publicações; d) artigos em outros idiomas que não o inglês.

Quadro 2- Resultados da estratégia de busca em cada base de dados

\begin{tabular}{|c|c|c|c|c|}
\hline Base de dados & Palavras-chave & Recuperados & Excluídos & Selecionados \\
\hline $\begin{array}{c}\text { Periódicos } \\
\text { CAPES }\end{array}$ & $\begin{array}{c}\text { Twice-exceptional OR gifted disabled AND intervention } \\
\text { OR supporting }\end{array}$ & $\mathrm{N}=823$ & $\mathrm{~N}=812$ & $\mathrm{~N}=11$ \\
\hline $\begin{array}{c}\text { Sage Journal } \\
\text { Twice-exceptional OR gifted disabled AND intervention } \\
\text { OR supporting }\end{array}$ & $\mathrm{N}=32$ & $\mathrm{~N}=30$ & $\mathrm{~N}=2$ \\
\hline \multicolumn{2}{|c|}{ Total } & $\mathrm{N}=13$ \\
\hline
\end{tabular}

Fonte: Elaboração das autoras.

$\mathrm{Na}$ triagem inicial, os resumos de todos os artigos recuperados foram lidos para verificar se atendia aos critérios de inclusão. O não atendimento aos critérios estabelecidos resultou na exclusão dos artigos. Em seguida, realizou-se a leitura completa de cada artigo e, depois, preencheu-se a ficha de protocolo para a coleta de dados, considerando os seguintes tópicos: autores, ano de publicação, tipos de intervenção, delineamento metodológico, objetivo e práticas socioemocionais.

A análise dos dados, buscando responder às questões de pesquisa, foi conduzida por etapas: a) análise textual na qual realizou-se a leitura completa dos artigos selecionados e registro das informações no protocolo de coleta de dados; b) análise temática, na qual foi realizada mais uma leitura dos artigos, buscando identificar as intervenções para os(as) estudantes duplamente excepcionais (SEVERINO, 
2002) e a etapa final constituiu em uma análise crítica dos estudos incluídos, com o objetivo de averiguar e ponderar o nível de validade das intervenções, para determinar a sua utilidade no atendimento às necessidades dos estudantes $2 \mathrm{E}$.

Para tanto, seguindo a classificação da Prática Baseada em Evidências, os estudos foram caracterizados de forma hierárquica, a depender do método adotado. Stetler et al. (1998) afirmaram, baseando-se nos delineamentos de pesquisa, que as evidências de um estudo podem ser classificadas em seis níveis: a) Nível 1 (evidências resultantes de meta-análise de vários estudos clínicos controlados e randomizados); b) Nível 2 (evidências obtidas em estudos individuais com delineamento experimental; c) Nível 3 (evidências de estudos quase-experimentais); d) Nível 4 (evidências de estudos descritivos não-experimentais - ou com abordagem qualitativa; e) Nível 5 (evidências provenientes de relatos de caso ou de experiência) e f) Nível 6 (evidências baseadas em opiniões de especialistas).

\section{Resultados e Discussão}

Os resultados e a discussão dos dados obtidos nesta revisão integrativa da literatura serão apresentados, levando-se em conta as questões de pesquisa. Para tanto, elegeram-se três temas: caracterização geral das produções publicadas de 2018 a 2020, abordagens teóricas que embasam as propostas de atendimento para estudantes $2 \mathrm{E}$ e práticas de atendimento no âmbito socioemocional.

\section{Caracterização geral das produções publicadas de 2018 a 2020}

No total, treze artigos $(\mathrm{N}=13)$ compuseram o corpus desta revisão. Desse total, quatro estudos $(\mathrm{N}=4)$ foram empíricos, perfazendo $30,8 \%$ da produção do período. Cinco estudos teóricos $(\mathrm{N}=5)$, escritos por especialistas da área, e quatro estudos de revisão $(N=4)$, que perfazem respectivamente $38,4 \%$ e 30,8\% da produção científica sobre o atendimento para os estudantes 2E (Cf. Quadro 3).

\begin{tabular}{|c|c|c|c|c|c|}
\hline $\begin{array}{c}\text { Base de } \\
\text { dados }\end{array}$ & $\begin{array}{c}\text { Ano/ } \\
\text { Periódico }\end{array}$ & Título & Autores & Método & Participantes \\
\hline $\begin{array}{c}\text { Periódicos } \\
\text { CAPES }\end{array}$ & $\begin{array}{c}2018 \\
\text { Gifted Child } \\
\text { Quarterly }\end{array}$ & $\begin{array}{l}\text { "Notbing fits exactly": } \\
\text { experiences of Asian } \\
\text { American parents of twice- } \\
\text { exceptional children }\end{array}$ & $\begin{array}{l}\text { Soeun Park; Megan } \\
\text { Foley-Nicpon; } \\
\text { Alyssa Choate e } \\
\text { Mallory Bolenbaugh }\end{array}$ & $\begin{array}{l}\text { Qualitativa } \\
\text { Survey }\end{array}$ & $\begin{array}{c}\text { Família } \\
N=11 \\
\text { Indianos }(n=2), \text { Coreanos } \\
(n=1), \text { Chineses }(n=2), \\
\text { Japoneses }(n=1), \text { Filipinos } \\
(n=4), \text { Tailandês }(n=1)\end{array}$ \\
\hline $\begin{array}{l}\text { Periódicos } \\
\text { CAPES }\end{array}$ & $\begin{array}{c}2018 \\
\text { The } \\
\text { Educational } \\
\text { Forum }\end{array}$ & $\begin{array}{l}\text { Seeing and supporting } \\
\text { twice-exceptional learners }\end{array}$ & $\begin{array}{c}\text { Chin-Wen Lee e } \\
\text { Jennifer A. Ritchotte }\end{array}$ & $\begin{array}{l}\text { Artigo } \\
\text { Teórico }\end{array}$ & --------- \\
\hline $\begin{array}{c}\text { Periódicos } \\
\text { CAPES }\end{array}$ & $\begin{array}{c}2018 \\
\text { International } \\
\text { Journal of } \\
\text { Special } \\
\text { Education }\end{array}$ & $\begin{array}{l}\text { Twice-exceptionality in the } \\
\text { Kingdom of Saudi } \\
\text { Arabia: policy } \\
\text { recommendations for } \\
\text { advances in Special } \\
\text { Education }\end{array}$ & Amra Mohammed & $\begin{array}{l}\text { Artigo } \\
\text { Teórico }\end{array}$ & --------- \\
\hline
\end{tabular}




\begin{tabular}{|c|c|c|c|c|c|}
\hline $\begin{array}{l}\text { Periódicos } \\
\text { CAPES }\end{array}$ & $\begin{array}{c}2019 \\
\text { International } \\
\text { Journal of } \\
\text { Special } \\
\text { Education }\end{array}$ & $\begin{array}{l}\text { Learning strategies for } \\
\text { twice-exceptional students }\end{array}$ & $\begin{array}{l}\text { Hannah Aqilah } \\
\text { Amran e Rosadah } \\
\text { Abd Majid }\end{array}$ & $\begin{array}{l}\text { Revisão } \\
\text { Sistemática } \\
\text { da } \\
\text { Literatura }\end{array}$ & --------- \\
\hline $\begin{array}{l}\text { Periódicos } \\
\text { CAPES }\end{array}$ & $\begin{array}{l}2019 \\
\text { Journal for } \\
\text { the } \\
\text { Education of } \\
\text { the Gifted }\end{array}$ & $\begin{array}{l}\text { A case study evaluation of } \\
\text { the implementation of } \\
\text { twice-exceptional } \\
\text { professional development } \\
\text { in Colorado }\end{array}$ & $\begin{array}{c}\text { Chin-Wen Lee e } \\
\text { Jennifer A. Ritchotte }\end{array}$ & $\begin{array}{l}\text { Qualitativa } \\
\text { Estudo de } \\
\text { Caso }\end{array}$ & $\begin{array}{c}\text { Escola/ } N=11 \\
\text { Professores }(n=7) \text { e } \\
\text { coordenadores } \\
\text { pedagógicos }(n=4)\end{array}$ \\
\hline $\begin{array}{l}\text { Periódicos } \\
\text { CAPES }\end{array}$ & $\begin{array}{l}2019 \\
\text { Journal for } \\
\text { the } \\
\text { Education of } \\
\text { the Gifted }\end{array}$ & $\begin{array}{l}\text { Learning experiences of } \\
\text { highly able learners with } \\
\text { ASD: using a success case } \\
\text { method }\end{array}$ & $\begin{array}{l}\text { I-Chen Wu, C. } \\
\text { Owen Lo e Kuei- } \\
\text { Fang Tsai }\end{array}$ & $\begin{array}{l}\text { Qualitativa } \\
\text { / } \\
\text { Estudo de } \\
\text { Caso }\end{array}$ & $\begin{array}{c}\text { Escola/ } \mathrm{N}=5 \\
\text { Estudante }(\mathrm{n}=2) \\
\text { Professor da sala regular } \\
(\mathrm{n}=1), \text { professor da } \\
\text { Educação Especial }(\mathrm{n}=1) \text {, } \\
\text { professor do Programa de } \\
\text { Educação de Dotados e } \\
\text { Talentosos }(\mathrm{n}=1)\end{array}$ \\
\hline $\begin{array}{l}\text { Periódicos } \\
\text { CAPES }\end{array}$ & $\begin{array}{l}2019 \\
\text { Gifted Child } \\
\text { Quarterly }\end{array}$ & $\begin{array}{l}\text { Coaching parents to use } \\
\text { bigher level questioning } \\
\text { with their twice- } \\
\text { exceptional children }\end{array}$ & $\begin{array}{c}\text { Jennifer A. Ritchotte } \\
\text { e Hasan Y. } \\
\text { Zaghlawan }\end{array}$ & $\begin{array}{l}\text { Quantitativ } \\
\text { a/ } \\
\text { Experimen } \\
\text { tal } \\
\text { Delineame } \\
\text { nto de } \\
\text { Sujeito } \\
\text { Único }\end{array}$ & $\begin{array}{c}\text { Família } \\
\mathrm{N}=8 \\
\text { Crianças }(\mathrm{n}=4), \\
\text { Pais }(\mathrm{n}=4)\end{array}$ \\
\hline $\begin{array}{l}\text { Periódicos } \\
\text { CAPES }\end{array}$ & $\begin{array}{l}2019 \\
\text { Gifted Child } \\
\text { Today }\end{array}$ & $\begin{array}{l}\text { Counselors and } \\
\text { psychologists mentoring } \\
\text { gifted black males with } \\
\text { disabilities to foster } \\
\text { College and career } \\
\text { readiness }\end{array}$ & $\begin{array}{l}\text { Renae D. Mayes, } \\
\text { Erik M. Hines, } \\
\text { Deidra L. Bibbs e } \\
\text { Jennifer Rodman }\end{array}$ & $\begin{array}{l}\text { Artigo } \\
\text { Teórico }\end{array}$ & --------- \\
\hline $\begin{array}{l}\text { Periódicos } \\
\text { CAPES }\end{array}$ & $\begin{array}{l}2020 \\
\text { The Journal } \\
\text { for specialists } \\
\text { in group } \\
\text { work }\end{array}$ & $\begin{array}{l}\text { College and career } \\
\text { readiness groups for gifted } \\
\text { black students with } \\
\text { disabilities }\end{array}$ & Renae D. Mayes & $\begin{array}{l}\text { Artigo } \\
\text { Teórico }\end{array}$ & --------- \\
\hline $\begin{array}{l}\text { Periódicos } \\
\text { CAPES }\end{array}$ & $\begin{array}{l}2020 \\
\text { Psychology } \\
\text { in the } \\
\text { Schools }\end{array}$ & $\begin{array}{l}\text { High ability students with } \\
\text { coexisting disabilities: } \\
\text { implications for school } \\
\text { psychological practice }\end{array}$ & $\begin{array}{l}\text { Megan Foley- } \\
\text { Nicpon e Susan G. } \\
\text { Assouline }\end{array}$ & $\begin{array}{l}\text { Artigo } \\
\text { Teórico }\end{array}$ & --------- \\
\hline $\begin{array}{l}\text { Periódicos } \\
\text { CAPES }\end{array}$ & $\begin{array}{c}2020 \\
\text { Gifted and } \\
\text { Talented } \\
\text { International }\end{array}$ & $\begin{array}{l}\text { Integrating creativity into } \\
\text { career interventions for } \\
\text { twice-exceptional students } \\
\text { in the United States: a } \\
\text { review of recente literature }\end{array}$ & $\begin{array}{c}\text { Ching-Lan Rosaline } \\
\text { Lin e Megan Foley- } \\
\text { Nicpon }\end{array}$ & $\begin{array}{l}\text { Revisão } \\
\text { Narrativa }\end{array}$ & ---------- \\
\hline $\begin{array}{c}\text { SAGE } \\
\text { Journal }\end{array}$ & $\begin{array}{c}2020 \\
\text { Professional } \\
\text { School } \\
\text { Counseling }\end{array}$ & $\begin{array}{l}\text { Leadership roles for schol } \\
\text { counselors in identifying } \\
\text { and supporting twice- } \\
\text { exceptional (2E) students }\end{array}$ & $\begin{array}{l}\text { Sara J. Renzulli e } \\
\text { Nicholas Gelbar }\end{array}$ & $\begin{array}{l}\text { Artigo } \\
\text { Teórico }\end{array}$ & --------- \\
\hline $\begin{array}{c}\text { SAGE } \\
\text { Journal }\end{array}$ & $\begin{array}{c}2020 \\
\text { Gifted } \\
\text { Education } \\
\text { International }\end{array}$ & $\begin{array}{l}\text { Parenting for strengths: } \\
\text { embracing the challenges of } \\
\text { raising children identified } \\
\text { as twice exceptional }\end{array}$ & $\begin{array}{c}\text { Sally M. Reis e Sara } \\
\text { J. Renzulli }\end{array}$ & $\begin{array}{l}\text { Artigo } \\
\text { Teórico }\end{array}$ & --------- \\
\hline
\end{tabular}

Fonte: Elaboração das autoras.

Considerando a relação entre as intervenções propostas para os estudantes $2 \mathrm{E}$ e os tipos de delineamento utilizados nas investigações, pode-se afirmar, como se verifica na Figura 1, que as propostas 
de intervenção para estudantes $2 \mathrm{E}$, em sua maioria, ainda têm se baseado em opiniões de especialistas ${ }^{3}$, o que equivale ao nível 6 na classificação proposta por Stetler et al. (1998). Isso significa dizer que não só houve uma escassez de estudos empíricos no recorte temporal de 2018 a 2020, mas também que as poucas investigações publicadas traduzem baixos níveis de evidência de que a utilização dos achados científicos possa realmente ser eficaz para a qualificação da prática educativa seja na família seja na escola para os estudantes $2 \mathrm{E}$.

Durante esse período, foi publicado apenas um estudo que utilizou um delineamento experimental, o que corresponde ao nível 2 de evidência. As demais investigações empíricas resultaram de pesquisas qualitativas de caráter descritivo, sendo uma delas classificada como survey, e duas, como estudos de caso, condizente aos níveis 4 e 5 respectivamente.

Figura 1- Classificação quanto ao nível de evidência da proposta de intervenção para os estudantes $2 \mathrm{E}$

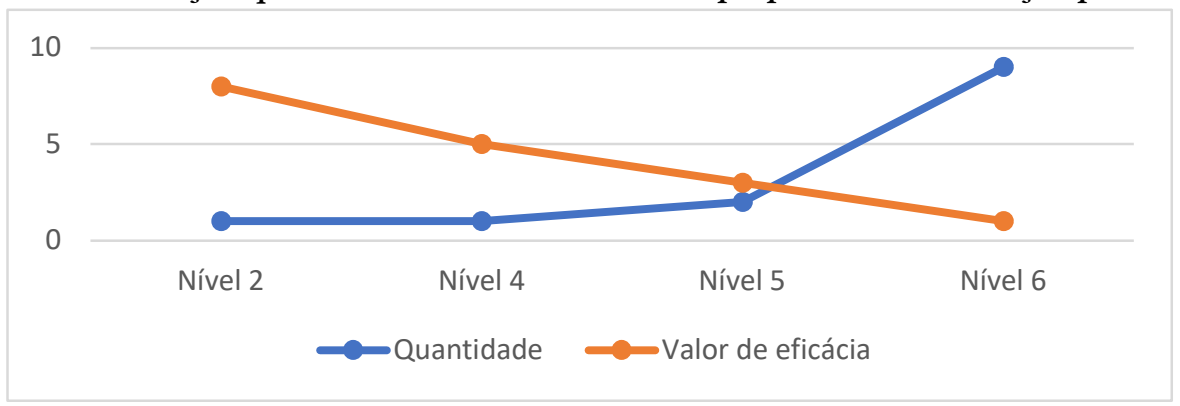

Fonte: Elaboração das autoras.

Dessa forma, os dados levantados, além de confirmarem poucas investigações empíricas sobre a identificação de estratégias específicas de intervenção para essa população de escolares (BAUM; SHADER; HÉBERT, 2014; FOLEY-NICPON, 2016; REIS; BAUM; BURKE, 2014), também corroboram o fato de que há poucas pesquisas utilizando delineamentos metodológicos mais rigorosos, tais como: meta-análise de vários estudos clínicos controlados e randomizados, delineamentos experimental e quase-experimental (CALLAHAN; MOON, 2007; RITCHOTTE; ZAGHLAWAN, 2019). A escassez de investigações sobre intervenção para esses estudantes constitui ainda uma lacuna no âmbito internacional e precisa, assim, ser mais contemplada e, inclusive, ser encarada como uma prioridade na área de educação de dotados e talentosos (FOLEY-NICPON et al., 2011).

Além disso, observa-se também que, dessas quatro pesquisas empíricas, duas delas tiveram como participantes a família e duas, os profissionais da escola com os estudantes. A intervenção com familiares e profissionais da escola, nesses estudos, corrobora a necessidade de que se estabeleça uma relação cooperativa entre essas instituições, sendo, pois, um fator que facilita o uso de estratégias de intervenção produtivas para estudantes $2 \mathrm{E}$ (KING, 2005).

\footnotetext{
${ }^{3}$ As revisões da literatura foram incluídas no nível 6 de evidência, tendo em vista que os autores dos artigos propuseram recomendações baseadas nas opiniões de especialistas.
} 
Convém, no entanto, ressaltar que, dos trezes estudos sobre intervenção para estudantes $2 \mathrm{E}$, apenas dois (Cf. Quadro 2) focalizaram as famílias desses estudantes, o que indica que há poucas investigações sobre as experiências familiares em relação a esse público (PARK et al., 2018). Conforme argumentam Besnoy et al. (2015), é fundamental à família a aquisição de conhecimentos sobre as características de seus filhos e sobre as políticas educacionais para atuarem em defesa dos direitos deles, principalmente considerando que, frequentemente, os pais de estudantes $2 \mathrm{E}$ enfrentam dificuldades na escola (poucas acomodações curriculares, serviços insuficientes de educação especial, poucas práticas relacionadas à aceleração e até insensibilidade da equipe técnico-pedagógica para atender as necessidades de estudantes com dupla excepcionalidade (PARK et al., 2018).

Segundo Park et al. (2018), é necessário o envolvimento da família não só nas intervenções que a escola precisa realizar para atender o perfil único de características desses estudantes, mas também no que se refere à orientação de seus filhos, para que eles possam desenvolver a perseverança, a automotivação, a autodefesa e as habilidades de adaptação. Dessa forma, infere-se que as poucas investigações envolvendo as intervenções na família de estudantes $2 \mathrm{E}$, ao longo do período pesquisado, podem ter impactos futuros, tais como, menos estabelecimento de relação cooperativa entre escola e familiares, menos conhecimento sobre as características de crianças e jovens $2 \mathrm{E}$ e menos defesa em relação aos direitos desses estudantes em âmbito educacional.

Os outros dois estudos empíricos que tiveram como participantes os profissionais da escola e os estudantes assumiram contornos distintos: um focalizou a relação das práticas de ensino com a aprendizagem e o desenvolvimento socioemocional de dois estudantes $2 \mathrm{E}$ e o outro destacou a formação profissional continuada de professores e de gestores da escola.

O primeiro estudo (WU; LO; TSAI, 2019) teve como participantes três professores, sendo um docente da sala regular, um, da sala de recursos e o outro, um professor do programa de educação para dotados e talentosos fornecido pela escola, e dois estudantes do ensino fundamental, com 11 anos, que foram identificados como dotados e talentosos e, ao mesmo tempo, com transtorno do espectro autista.

O objetivo central da investigação foi explorar as experiências de aprendizagem positivas para esses estudantes, tendo em vista a elaboração de estratégias efetivas que pudessem melhor atender às necessidades de aprendizagem e o desenvolvimento socioemocional. Para tanto, os autores realizaram entrevistas, observações na escola e coletaram dados por meio de questionários e relatórios escolares. Wu, Lo e Tsai (2019) concluíram que as experiências de aprendizagem positivas desses dois estudantes estavam relacionadas à construção de contexto escolar inclusivo que promoveu flexibilidade curricular, uma abordagem de ensino focada nos pontos fortes, no talento de cada estudante e um ambiente socioemocional seguro para eles no relacionamento com os colegas e com os professores.

No segundo estudo, Lee e Ritchotte (2019) propuseram a formação continuada de onze profissionais (sete educadores e quatro gestores) em uma escola do Colorado. O objetivo da investigação foi avaliar a implementação de um curso de formação continuada sobre estudantes $2 \mathrm{E}$ que funcionou 
durante dois anos, de 2014 a 2016. As autoras realizaram entrevistas e coletaram dados de documentos escolares. Lee e Ritchotte (2019) chegaram à conclusão de que é fundamental tanto na formação inicial quanto na formação profissional continuada de professores e gestores o estudo sobre a dupla excepcionalidade e as características de estudantes $2 \mathrm{E}$, para construir estratégias eficazes que venham a apoiar as necessidades acadêmicas e socioemocionais desse público no contexto escolar.

Os dados coletados sobre os participantes das pesquisas nos estudos empíricos ratificam que, no trabalho de intervenção com os estudantes $2 \mathrm{E}$, é necessária uma equipe de trabalho multiprofissional com a pareceria dos pais (BAUM; SHADER; HÉBERT, 2014; COLEMAN; GALLAGHER, 2015). Deve ser, portanto, planejado e executado em múltiplas frentes e deve envolver as famílias, os professores da sala de aula regular, os professores da educação especial, os professores especializados em educação de dotados e talentosos ${ }^{4}$, os gestores, os coordenadores, os psicólogos, o terapeuta ocupacional, o assistente social e o educador físico (TRAIL, 2011).

De acordo com Coleman e Gallagher (2015), a formação dessa equipe e o desenvolvimento de trabalho cooperativo para atender aos estudantes $2 \mathrm{E}$, no entanto, requer uma infraestrutura, que depende das políticas públicas, da consultoria especializada, da formação profissional continuada e da disponibilização de recursos financeiros. Sem essa infraestrutura, o atendimento às necessidades educacionais desses estudantes fica comprometido, pois não se consegue colocar em funcionamento um trabalho cooperativo com os pais, a equipe escolar e a equipe de profissionais especializados para o desenvolvimento de serviços que promovam o sucesso escolar desses alunos (BAUM; SHADER; OWEN, 2017; COLEMAN; GALLAGHER, 2015).

Por essa razão, possivelmente, na análise dos treze estudos, verificaram-se vários temas: experiências de aprendizagem bem-sucedidas, orientações às famílias, influência da etnia dos pais nas experiências educacionais com os filhos $2 \mathrm{E}$, programa de formação continuada para a equipe técnico pedagógica da escola, elaboração de políticas públicas, carreira profissional e a Educação Superior, dentre outros (Cf. Figura 2).

\footnotetext{
${ }^{4}$ Nos Estados Unidos e em outros países, a educação de dotados e talentosos constitui uma área especializada de investigação separada da Educação Especial, embora inter-relacionada a essa última. No Brasil, no entanto, estudantes dotados e talentosos constituem o público da Educação Especial (BRASIL, 2011). A separação, no texto, ocorre não só pelo respeito à citação indireta do autor, mas também porque reconhece-se que nem todos os professores com a formação em Educação Especial, no nosso país, têm conhecimentos suficientes para atuarem com os alunos dotados e talentosos e, por consequência, com aqueles identificados com dupla excepcionalidade.
} 
Figura 2 - Temas abordados nos artigos

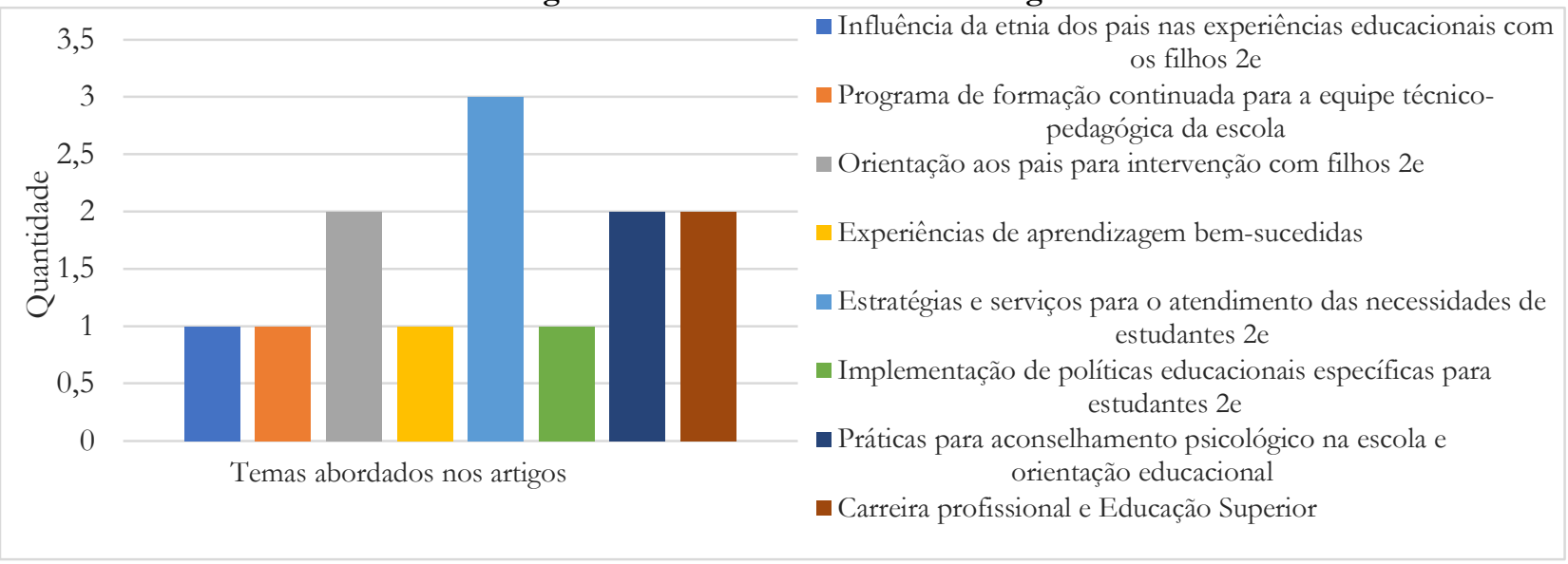

Fonte: Elaboração das autoras.

A variedade de temas parece estar relacionada à complexidade da coexistência de duas excepcionalidades que desenham um perfil único, simultâneo e paradoxal de características, o que implica na elaboração e na oferta de serviços que considerem padrões individuais de necessidades educacionais (COLEMAN; GALLAGHER, 2015; TRAIL, 2011). Pode-se inferir, a partir desse dado, que a proposição de serviços educacionais será diferenciada para cada estudante e dependerá da combinação das duas excepcionalidades e constitui um grande desafio para a escola. Segundo Baum, Shader e Owen (2017, p.17), é necessário "Entender o que ocorre quando se trabalha com a combinação das duas excepcionalidades para determinar as necessidades emocionais e educacionais de estudantes $2 \mathrm{E}$ ".

$\mathrm{Na}$ Figura 3, nota-se que, em 61,5\% das produções científicas, as intervenções propostas abrangem, ao mesmo tempo, dois tipos de intervenção - acadêmicas e socioemocionais -. Dos demais artigos, apenas dois abordaram as intervenções socioemocionais e três, somente as acadêmicas, perfazendo, respectivamente, 15, 4\% e 23\% da produção publicada ao longo do período.

Percebe-se, portanto, que os dados coletados coadunam com os argumentos de vários estudiosos da temática (BALDWIN, L. et al., 2015; BAUM; SHADER; HÉBERT, 2014; BAUM; SHADER; OWEN, 2017; COLEMAN; GALLAGHER, 2015; FOLEY-NICPON et al., 2011; KING, 2005; REIS; BAUM; BURKE, 2014; TRAIL, 2011), os quais argumentam que é fundamental a proposta de serviços que atendam a duplicidade de necessidades educacionais, ou seja, programas de desenvolvimento do talento, respeitando as áreas de interesse e os pontos fortes de cada estudante, e atendimentos psicoeducacionais especializados para remediação das necessidades socioemocionais e de aprendizagem. 


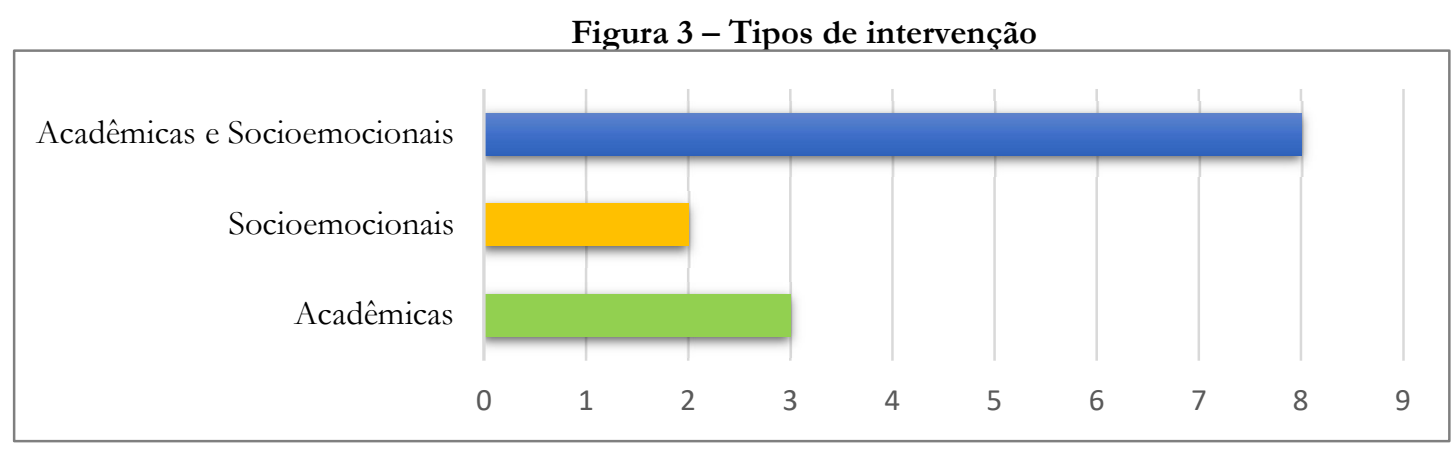

Fonte: Elaboração das autoras.

Outro aspecto interessante a ser destacado das investigações é o contexto social em que as intervenções se inserem. Em síntese, observou-se que, para esse público de escolares, de maneira imprescindível, é necessário que elas envolvam tanto o contexto microssocial (família e a escola do estudante) quanto o contexto macrossocial (leis e políticas educacionais, etnia e cultura dos pais e filhos, carreira profissional).

Todos esses contextos interferem no desenvolvimento e na aprendizagem dos estudantes $2 \mathrm{E}$. Embora é sabido que a organização familiar e o ambiente escolar afetam diretamente cada estudante com ou sem dupla excepcionalidade, verificou-se, durante a análise dos dados de cada artigo, que os papéis desempenhados pela família e escola, a constituição étnica e cultural dos pais e o conhecimento sobre dupla excepcionalidade dos familiares e profissionais da escola interferem decisivamente na efetivação das políticas educacionais, isto é, na garantia de que os direitos desses estudantes sejam atendidos na instituição escolar (BESNOY et al., 2015; PARK et al., 2018).

Além disso, vale destacar ainda que a elaboração de leis e políticas públicas constitui, no contexto macrossocial, um fator de suma importância para que as práticas de atendimento sejam, de fato, realizadas no contexto microssocial da escola. Conforme argumenta Mohammed (2018), sem o estabelecimento de uma política educacional que assegure aos estudantes $2 \mathrm{E}$ os serviços educacionais necessários ao pleno desenvolvimento de seu potencial, nenhum serviço pode ser oferecido, para que esses estudantes aprendam e se desenvolvam, o que pode levar a perda de potenciais humanos valiosos para a sociedade (LEUROUX; LEVITT'PERLMAN, 2000).

Outro dado que merece ser ressaltado diz respeito aos fatores culturais e às etnias dos pais e filhos. De acordo com Park et al. (2018), o contexto sociocultural dos pais, incluindo a etnia, podem influenciar nas práticas parentais na educação dos filhos 2E. Nesse estudo, os autores demonstram que os pais americanos, com origem cultural asiática, tiveram que desenvolver resiliência e esforço persistente de defesa enquanto compreendiam as características complexas da dupla excepcionalidade. Os resultados desta investigação revelaram também que esses pais perderam a fé no sistema educacional quando perceberam que os educadores e a equipe gestora da escola não compreendiam completamente a duplicidade de necessidades de seus filhos, isto é, a escola não focalizava igualmente as áreas de interesse, 
as capacidades elevadas e as dificuldades advindas de alguma deficiência ou de algum transtorno/distúrbio ou de uma síndrome.

Além disso, dois estudos (MAYES et al., 2019; MAYES, 2020) apontaram que estudantes negros, além de serem sub-representados em programas para dotados e talentosos, frequentemente enfrentam barreiras acadêmicas que impedem a preparação para a faculdade e a carreira profissional. De acordo com Mayes et al. (2019), quando esses estudantes são selecionados para participarem de programas de desenvolvimento do talento, acabam recebendo mensagens negativas a respeito de suas capacidades, fruto de percepções equivocadas sobre a dupla excepcionalidade e de visões estereotipadas.

Dessa forma, Mayes et al. (2019) e Mayes (2020) argumentam que os estudantes afrodescendentes e com dupla excepcionalidade estão embutidos em um contexto sociocultural único que deve ser considerado na promoção das práticas de atendimento, sendo, pois, necessário intervir nas dificuldades socioemocionais ainda mais salientes por conta das representações sociais estereotipadas e preconceituosas. Além disso, esses autores também apontam para a necessidade de que o psicólogo escolar desempenhe um papel de liderança, trabalhando em parceria com os pais, professores e demais estudantes, a fim de que os estudantes afrodescendentes e com dupla excepcionalidade encontrem um ambiente socioemocional e acadêmico seguro para o desenvolvimento de seus talentos.

\section{Abordagens teóricas que embasam as propostas de intervenção para estudantes $2 \mathrm{E}$}

Muito comum, na prática de intervenção, que os estudantes $2 \mathrm{E}$ sejam atendidos, visando à remediação dos déficits devido à deficiência ou ao transtorno/distúrbio, para que alcance o padrão, visto que seus potenciais, dificilmente, são reconhecidos (RANGNI; COSTA, 2014; RENZULLI; GELBAR, 2020).

Isso equivale a dizer que a oferta de serviços de enriquecimento curricular e/ou programas para o desenvolvimento do talento ainda tem sido negada aos estudantes $2 \mathrm{E}$, pois muitos profissionais da escola focalizam, principalmente, os problemas de aprendizagem e supõem que esses estudantes não tenham condições de frequentar programas para o desenvolvimento do talento e nem condições de serem acelerados na escola (NEIHART, 2008).

Historicamente, esse tipo de abordagem focado nos déficits expandiu mesmo quando a Educação Especial passou a incluir os estudantes com capacidades intelectuais elevadas. O foco da intervenção era determinado pelo que os estudantes não poderiam fazer, nos problemas de aprendizagem e atenção que eles apresentavam, e o objetivo central da intervenção era remediar, compensar esses problemas e déficits (BAUM; SHADER, 2020).

A abordagem baseada nos déficits, enfatizando apenas a deficiência ou o transtorno, ganhou vida própria quando Kirk e Bateman cunharam o termo transtornos de aprendizagem em 1962 (BAUM; SHADER, 2020). Essas autoras afirmam que, apesar de Gallagher, mais tarde, em 1986, ter cunhado o termo dupla 
excepcionalidade e reconhecido que estudantes dotados e talentosos também apresentam transtornos de aprendizagem ao mesmo tempo, a ênfase da intervenção ainda estava focada em abordar as dificuldades de aprendizagem e os déficits de atenção como a primeira ação da intervenção, sem qualquer consideração a respeito das capacidades elevadas dos estudantes.

Em contrapartida a essa realidade, vários estudiosos (BAUM; SHADER; HÉBERT, 2014; BAUM, SHADER; OWEN, 2017; COLEMAN; GALLAGHER, 2015; FOLEY-NICPON et al., 2011; KING, 2005; OWENS et al., 2016; REIS; BAUM; BURKE, 2014; TRAIL, 2011) argumentam que a primeira medidade de apoio aos estudantes $2 \mathrm{E}$ deve ser a oferta de serviços focalizados nos talentos, nas áreas de interesse, porque promovem resultados eficazes para o desenvolvimento cognitivo, social e emocional dos estudantes com $2 \mathrm{E}$.

$\mathrm{Na}$ análise dos treze artigos selecionados, verificou-se que a abordagem focada no talento e nos interesses desses estudantes constitui a concepção primordial para promover a intervenção. Todas as recomendações, estratégias, práticas e programas se basearam na abordagem focada nos talentos e nos interesses dos estudantes 2E, corroborando, dessa maneira, a eficácia dessa abordagem já bastante defendida na literatura da área (BAUM; SHADER; HÉBERT, 2014; BAUM, SHADER; OWEN, 2017; COLEMAN; GALLAGHER, 2015; FOLEY-NICPON et al., 2011; KING, 2005; OWENS et al., 2016; REIS; BAUM; BURKE, 2014; TRAIL, 2011).

Vale frisar que a abordagem focada no talento é composta por cinco pilares em que a intervenção deve ser ancorada: 1) ambiente escolar deve ofertar segurança psicológica (fornecer um ambiente que seja propício para que os estudantes $2 \mathrm{E}$ recuperem a autoestima, a autoconfiança e desenvolvam a autoaceitação); 2) tempo/ritmo deve ser respeitado (permitir o progresso dos estudantes, o ritmo de cada um sem pressa ou pressões para que tenha um desempenho equiparado ao nível da série); 3) tolerância para a assincronia; 4) manutenção de relações positivas e 5) foco no desenvolvimento do talento (BAUM; SHADER; HÉBERT, 2014; BAUM, SHADER; OWEN, 2017).

Nota-se, assim, que os achados desta revisão, além de corroborar os diversos estudos que defendem a abordagem de intervenção focada nos talentos e interesses dos estudantes $2 \mathrm{E}$, também assinalam uma mudança de paradigma (BAUM; SHADER; HÉBERT, 2014; RENZULLI; GELBAR, 2020), tendo em vista que, ao longo do período pesquisado, os trezes estudos não só se apoiaram nessa abordagem, como também assinalaram as desvantagens de se centrar na abordagem do déficit na intervenção de estudantes $2 \mathrm{E}$.

É necessário enfatizar que a abordagem focada nos talentos, nos interesses dos estudantes $2 \mathrm{E}$ não negligencia suas dificuldades ou as áres deficitárias. Esse modelo, no entanto, em vez de trabalhar na remediação das dificuldades como primeira estratégia de ação, centraliza esforços para identificar os talentos e interesses e, a partir disso, procura elaborar um programa de intervenção com apoios que assegurem tanto o sucesso acadêmcio da criança ou do jovem $2 \mathrm{E}$ e quanto o seu bem-estar 
socioemocional (BALDWING et al., 2015; BAUM; SHADER; HÉBERT, 2014; BAUM; SHADER; OWEN, 2017).

Além disso, verificou-se que a abordagem focada no talento, nos interesses desses estudantes minimizam os problemas comportamentais e de aprendizagem, desenvolvendo a autoestisma, o autoconecito e a autoeficácia (BAUM; SHADER; HÉBERT, 2014; MAYES et al., 2019; MAYES, 2020; PARK et al., 2018; RENZULLI; GELBAR, 2020; REIS; RENZULLI, 2020; LIN; FOLEY-NICPON, 2020).

Os resultados também indicaram uma outra concepção teórica, não excludente à abordagem focada nos talentos, que foi utilizada como fundamento para apoiar as intervenções com os estudantes 2E. No estudo de Lin e Foley-Nicpon (2020), essas autoras propõem a arte e a criatividade como estratégias de intervenção, visando à carreira profissional, para esses estudantes e apoiam tanto na abordagem focada nos talentos quanto nos postulados da Psicologia Positiva.

Sabe-se que a Psicologia Positiva trata do estudo de sentimentos, emoções, instituições e comportamentos positivos, cuja meta é a felicidade humana (SELIGMAN, 2004 apud SCORSOLINICOMIN; SANTOS, 2010). Então, por meio dessas duas abordagens, essas autoras, embora ressaltem a necessidade de mais estudos empíricos, defendem que integrar a criatividade e a arte nas intervenções com estudantes $2 \mathrm{E}$ sobre a carreira profissional, pode encorajá-los a considerar suas singularidades, interesses, valores e ajudá-los a superar os desafios.

\section{Práticas de atendimento às necessidades socioemocionais de estudantes $2 \mathrm{E}$}

$\mathrm{Na}$ análise dos artigos, foram identificados seis tipos de apoios que promovem o desenvolvimento e o bem-estar socioemocional dos estudantes 2E. Pode-se verificar uma síntese, no Quadro 4, das intervenções encontradas nas produções científicas.

Quadro 4 - Síntese das práticas de atendimento no âmbito socioemocional

\begin{tabular}{|c|c|c|c|}
\hline Local & Necessidades & Práticas de atendimento & Resultados \\
\hline 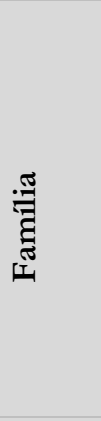 & Apoio familiar & $\begin{array}{l}\text { Fornecer ajuda e combinar estratégias nas dificuldades } \\
\text { acadêmicas e emocionais; } \\
\text { Ensinar estratégias de compensação; } \\
\text { Trabalhar em cooperação com a escola; } \\
\text { Conhecer as características dos indivíduos duplamente } \\
\text { excepcionais e os perfis únicos dos filhos; } \\
\text { Mudar o paradigma da educação dos filhos (em vez de } \\
\text { focalizar os déficits e os problemas, deve promover ações } \\
\text { para desenvolver os talentos, os pontos fortes e os } \\
\text { interesses dos filhos). }\end{array}$ & $\begin{array}{l}\text { 1. Desenvolvimento } \\
\text { social e emocional }\end{array}$ \\
\hline 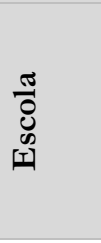 & $\begin{array}{l}\text { Apoio } \\
\text { multiprofissional }\end{array}$ & $\begin{array}{l}\text { - Trabalho colaborativo (psicólogo da escola, } \\
\text { diretor, professor, coordenador e outros } \\
\text { profissionais que se fizerem necessários); } \\
\text { Compartilhamento e resolução de problemas em } \\
\text { equipe; }\end{array}$ & $\begin{array}{l}\text { 1. Construção de } \\
\text { ambiente escolar } \\
\text { psicologicamente } \\
\text { seguro e sensível às } \\
\text { necessidades } \\
\text { socioemocionais }\end{array}$ \\
\hline
\end{tabular}




\begin{tabular}{|c|c|c|}
\hline $\begin{array}{l}\text { Apoio do(a) } \\
\text { professor(a) }\end{array}$ & $\begin{array}{l}\text { - Formação interdisciplinar para entendimento das } \\
\text { características de estudantes 2E e das } \\
\text { necessidades acadêmicas e socioemocionais; } \\
\text { Desenvolvimento das estratégias baseadas no } \\
\text { talento e nos interesses dos estudantes } 2 \mathrm{E} \\
\text { 1. Criação de ambiente psicologicamente seguro; } \\
\text { 2. Desenvolvimento de relações interpessoais } \\
\text { positivas; } \\
\text { 3espeito ao ritmo e ao tempo de cada estudante } \\
\text { 2E; } \\
\text { Entendimento do que significa o } \\
\text { desenvolvimento assincrônico acentuado de } \\
\text { estudantes 2E; } \\
\text { Incentivo para que os estudantes invistam tempo } \\
\text { em tópicos de seu interesse. } \\
\text { Planejamento deve ter o foco nas altas } \\
\text { capacidades e nas práticas de atendimento } \\
\text { específicas para estudantes dotados e talentosos } \\
\text { (enriquecimento, aceleração dentre outros); } \\
\text { Utilização de práticas de ensino bem-sucedidas } \\
\text { (desenho universal para aprendizagem, } \\
\text { diferenciação curricular, } \\
\text { curricular); flexibilização } \\
\text { Conhecimento sobre a dupla excepcionalidade } \\
\text { deve mudar a percepção que os professores têm } \\
\text { desses alunos. }\end{array}$ & $\begin{array}{l}\text { 1. } \begin{array}{l}\text { Melhoria do } \\
\text { desempenho } \\
\text { acadêmico, da } \\
\text { autoestima, da } \\
\text { autoeficácia; }\end{array} \\
\text { 2. } \begin{array}{l}\text { Desenvolvimento } \\
\text { socioemocional; }\end{array} \\
\text { 3. } \begin{array}{l}\text { Experiências positivas } \\
\text { de aprendizagem; }\end{array} \\
\text { 4. } \begin{array}{l}\text { Melhoria das relações } \\
\text { com os colegas e } \\
\text { professores } \\
\text { relacionamento de } \\
\text { confiança }\end{array}\end{array}$ \\
\hline $\begin{array}{c}\text { Apoio de colegas } \\
\text { de classe }\end{array}$ & - Ajuda dos colegas de classe. & $\begin{array}{l}\text { 1. } \begin{array}{l}\text { Desenvolvimento de } \\
\text { relações positivas e } \\
\text { saudáveis; } \\
\text { 2. Diminuição de } \\
\text { rótulos, críticas e } \\
\text { estereótipos; } \\
\text { 3. Construção de uma } \\
\text { identidade positiva e } \\
\text { comportamento pró- } \\
\text { social; } \\
\text { Melhoria } \\
\text { desempenho do } \\
\text { acadêmico. }\end{array}\end{array}$ \\
\hline $\begin{array}{c}\text { Apoio do } \\
\text { psicólogo escolar } \\
\text { ou do orientador } \\
\text { educacional }\end{array}$ & $\begin{array}{l}\text { - Papel de destaque na avaliação psicoeducacional, } \\
\text { na identificação e no atendimento aos estudantes } \\
\text { 2E; } \\
\text { - Responsável pela elaboração de um programa de } \\
\text { aconselhamento (individual ou em grupo) nas } \\
\text { escolas; } \\
\text { - Atuação de liderança na defesa das práticas } \\
\text { educacionais para os estudantes } 2 \mathrm{E} \text {; } \\
\text { - Sensibilização dos demais profissionais da escola } \\
\text { para que atuem como agentes de apoio aos } \\
\text { estudantes } 2 \mathrm{E} ; \\
\text { Uso da arte como forma de comunicação tanto } \\
\text { dos potenciais quanto das dificuldades } \\
\text { emocionais; } \\
\text { Aconselhamento psicológico na escola. }\end{array}$ & $\begin{array}{l}\text { 1. } \begin{array}{l}\text { Desenvolvimento } \\
\text { socioemocional; } \\
\text { 2. } \\
\text { Melhoria das } \\
\text { habilidades sociais; } \\
\text { 3. } \\
\text { Melhoria da } \\
\text { autoeficácia, da } \\
\text { autoestima } \\
\text { 4. Melhora } \\
\text { autoconsciência, } \\
\text { autoanálise, } \\
\text { entendimento das } \\
\text { barreiras externas; } \\
\text { Cultivo de resiliência e } \\
\text { força. }\end{array}\end{array}$ \\
\hline $\begin{array}{c}\text { Apoio da } \\
\text { Coordenação } \\
\text { pedagógica }\end{array}$ & 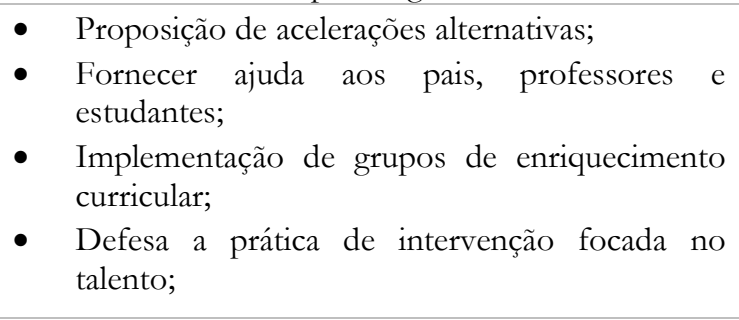 & $\begin{array}{l}\text { 1. Ambiente escolar } \\
\text { psicologicamente } \\
\text { seguro e sensível às } \\
\text { necessidades } \\
\text { socioemocionais; do } \\
\text { 2. Melhoria desempenho } \\
\text { deseratêmico; }\end{array}$ \\
\hline
\end{tabular}


- Atuação direta com estudantes $2 \mathrm{E}$ ensinando-os a aprenderem estratégias de compensação, habilidades de estudo, a planejarem a carreira profissional e a tomarem decisões.

Fonte: Elaboração das autoras.

Os resultados encontrados revelam que as intervenções, no âmbito socioemocional, são necessárias não só para o bem-estar socioemocional dos estudantes $2 \mathrm{E}$ como também para a melhoria do desempenho acadêmico. No entanto, é necessário ressaltar que a maioria das propostas expostas no Quadro 4 baseiam-se na opinião de especialistas na temática e em estudos de caso, o que diminui consideravelmente o valor dos achados científicos para identificar as estratégias e práticas de intervenção que são efetivas para esses alunos, tendo em vista que não são, em grande parte, resultados de pesquisas empíricas com uso de delineamentos metodológicos mais rigorosos (Cf. Figura 1) (CALLAHAN; MOON, 2007).

Os dados encontrados revelam que há poucas evidências empíricas sobre as práticas de aconselhamento específicas para os estudantes 2E (FOLEY-NICPON; ASSOULINE, 2015), apesar de ser amplamente confirmado de que a assincronia acentuada de estudantes 2E corrobora para mais dificuldades socioemocionais do que aquelas apresentadas pelos estudantes dotados e talentosos apenas (LOVECKY, 2004; WEBB et al., 2016).

Dessa forma, pode-se afirmar que, ainda no contexto internacional, na área de dotação e talento, são necessárias pesquisas que demonstrem relações causais e de intervenção que envolvam estratégias de aprendizagem específicas para os estudantes 2E (FOLEY-NICPON; ASSOULINE; COLANGELO, 2013; RITCHOTTE; ZAGHLAWAN, 2019).

\section{Considerações finais}

Estudantes 2E necessitam de diversos apoios, na escola e na família, por meio de um trabalho cooperativo, para promover o seu desenvolvimento cognitivo, social e emocional. Foi possível inferir que os serviços de apoio a esses estudantes devem considerá-los como um todo, incluindo, ao mesmo tempo, estratégias de intervenção acadêmicas e socioemocionais. Notou-se também que as intervenções socioemocionais são cruciais para o bem-estar psicológico e social assim como para a melhoria do desempenho acadêmico de estudantes $2 \mathrm{E}$.

Mesmo considerando as limitações deste estudo (recorte temporal de três anos, busca em apenas dois bancos de dados e em um único idioma), pode-se afirmar que as pesquisas sobre intervenção socioemocional não são apenas escassas, mas também insuficientes para estabelecer relações causais, resultantes de delineamentos experimentais e/ou quase-experimentais, já que a maioria dos estudos selecionados ainda baseia suas recomendações e sugestões de intervenção em estudos de caso e opiniões de especialistas. 
Desse modo, estudos futuros devem considerar a ampliação do recorte temporal e dos bancos de dados. Além disso, verifica-se a necessidade de realização de pesquisas com intervenção para esse público, principalmente, com delineamentos experimentais e/ou quase-experimentais, tendo em vista a necessidade de evidências mais eficazes para a prática educacional.

\section{REFERÊNCIAS}

AMRAN, Hannah; MAJID, Rosadah. Learning strategies for twice-exceptional students. International Journal of Special Education, v. 33, n.4, p. 954-976, 2019. Disponível em: https:// files.eric.ed.gov/fulltext/EJ1219411.pdf. Acesso em: 05 jun.2021.

BALDWIN, Lois; BAUM, Susan; PERELES, Daphne; HUGHES, Claire. Twice-exceptional learners: the journey toward a shared vision. Gifted Child Today, v. 38, n. 4, p. 206-214, 2015. Disponível em: http://sagepub.com/journalsPermissions.nav. Acesso em: 15 abr. 2018.

BAUM, Susan. Introduction to twice-exceptional and special populations of gifted students. In BAUM, S. (Ed.). Twice-exceptional and special populations of gifted students. USA: National Association for Gifted Children, 2004, p. 23-33.

BAUM, Susan; SCHADER, Robin; HÉBERT, Thomas. Through a different lens: reflecting on strengthsbased, talent-focused approach for twice-exceptional learners, Gifted Child Quarterly, v. 58, n. 4, p. 311 327, 2014. Disponível em: https://sci-hub.tw/https://doi.org/10.1177/0016986214547632. Acesso em: 29 mar. 2020.

BAUM, Susan; SCHADER, Robin; OWEN, Steven. To be gifted and learning disabled: strenght-based strategies for helping twice- exceptional students with LD, ADHD, ASD, and more. USA: Waco, TX: Prufrock Press, 2017.

BAUM; Susan; SCHADER, Robin. Twice-exceptionality: a field whose time has come. In: FUGATE, Matthew; BEHRENS, Wendy; BOSWELL, Cecelia. Understanding twice-exceptional learners: connecting research to practice. United States: Prufrock Press, 2020, p. 7-31.

BESNOY, Kevin; SWOSZOWSKI, Nicole; NEWMAN, Jane; FLOYD, Amanda; JONES, Parrish; BYRNE, Caitlin. The advocacy experiences of parents of elementary age, twice-exceptional children, Gifted Child Quarterly, v. 59, p. 108-123, 2015. Disponível em: https://scihub.se/https://doi.org/10.1177\%2F0016986215569275. Acesso em: 18 jun. 2021.

BRASIL. Decreto 7.611/2011. Dispõe sobre a educação especial, o atendimento educacional especializado e dá outras providências. Brasília: MEC, 2011. Disponível em: http://www.prograd.ufu.br/sites/prograd.ufu.br/files/media/documento/8.6 - decreto ndeg 7.611 11 - acessib.pdf. Acesso em: 01 ago. 2018.

CALLAHAN, Carolyn; MOON, Tonya. Sorting the wheat from the chaff: what makes for good evidence of effectiveness in the literature in gifted education?, Gifted Child Quarterly, v. 51, p. 305-319, 2007. Disponível em: https://sci-hub.se/https://doi.org/10.1177\%2F0016986207306317. Acesso em: 24 jun. 2021. 
COLEMAN, Mary Ruth; GALLAGHER, Shelagh. Meeting the needs of students with 2E: it takes a team. Gifted Child Today, v. 38, n. 4, p. 252-254, 2015. Disponível em: https://scihub.tw/https://doi.org/10.1177\%2F1076217515597274. Acesso em: 12 mar. 2019.

CORDEIRO, Alexander; OLIVEIRA, Gloria Maria de; RENTERÍA, Juan Miguel; GUIMARÃES, Carlos Alberto. Revisão sistemática: uma revisão narrativa. Rev. Col. Bras. Cir., v. 34, n. 6, p. 428-431, 2007. Disponível em:

https://www.scielo.br/j/rcbc/a/CC6NRNtP3dKLgLPwcgmV6Gf/?format=pdf\&lang=pt. Acesso em: 25 mar. 2021.

FOLEY-NICPON, Megan; ALLMON, Allison; STINSON, Rebecca; SIECK, Barbara. Empirical Investigation of Twice-Exceptionality: Where Have We Been and Where Are We Going?, Gifted Child Quarterly, v. 55, n. 1, 2011, p. 3-17. Disponível em: http://gcq.sagepub.com. Acesso em: 15 abr. 2018.

FOLEY-NICPON, Megan; ASSOULINE, Susan; COLANGELO, Nicholas. Twice-Exceptional Learners: who needs to know what?, Gifted Child Quarterly, v. 57, n. 3, p. 169-180, 2013. Disponível em: https://sci-hub.se/https://doi.org/10.1177\%2F0016986213490021. Acesso em: 18 jun. 2020.

FOLEY-NICPON, Megan; ASSOULINE, Susan. Counseling considerations for the twice-exceptional client, Journal of Counseling \& Development, v. 93, n. 2, p. 202-211, 2015. Disponível em: https://scihub.se/https://doi.org/10.1002/j.1556-6676.2015.00196.x. Acesso em: 21 jun. 2021.

FOLEY-NICPON, Megan. The social and emotional development of twice-exceptional children. In: NEIHART, Maureen; PFEIFFER, Steven; CROSS, Tracy (Eds.). The social and emotional development of gifted children: what do we know?.Texas: Prufrock Press Inc Waco, 2016, p. 103-118.

FOLEY-NICPON, Megan; ASSOULINE, Susan. High ability students with coexisting disabilities: implications for school psychological practice, Psychology in the Schools, p. 1-12, 2020. Disponível em: https://sci-hub.se/https://doi.org/10.1002/pits.22342. Acesso em: 15 maio 2021.

GAGNÉ, Francoys. Giftedness and talent: reexamining a reexamination of the definitions, Gifted Child Quarterly, v. 29, n.3, p.103-112, $1985 . \quad$ Disponível em: https://www.researchgate.net/publication/254092876 Giftedness and Talent Reexamining a Reexa mination of the Definitions. Acesso em: 10 jun. 2019.

KAUFMAN, Scott Barry. Twice exceptional: supporting and educating bright and creative students with learning difficulties. Canada: Oxford University Press, 2018.

KING, Emily Willians. Addressing the social and emotional needs of twice-exceptional students. TEACHING Exceptional Children, v. 38, n.1, p. 16-20, 2005. Disponível em: https://scihub.se/https://doi.org/10.1177\%2F004005990503800103. Acesso em: 15 maio 2021.

LEE, Chin-Wen; RITCHOTTE, Jennifer. Seeing and supporting twice-exceptional learners. The Educational Forum, v. 82, n.1, p. 68-84, 2018. Disponível em: https://scihub.se/https://doi.org/10.1080/00131725.2018.1379580. Acesso em: 15 maio 2021.

LEE, Chin-Wen; RITCHOTTE, Jennifer. A case study evaluation of the implementation of twiceexceptional professional development in Colorado, Journal for the Education of the Gifted, p. 1-26, 2019. Disponível em: https://sci-hub.se/https://doi.org/10.1177\%2F0162353219874440. Acesso em: 15 maio 2021. 
LEROUX, Janice; LEVITT-PERLMAN, Marla. The gifted child with attention deficit disorder:An identification and intervention challenge. Roeper Review, v. 22, n. 3, p. 171-176, 2000. Disponível em: https://sci-hub.se/https://doi.org/10.1080/02783190009554028. Acesso em: 18 jun. 2018.

LOVECKY, Deirdre. Different minds: gifted children with AD/HD, Asperger Syndrome, and other learning deficits. London: Jessica Kingsley Publishers, 2004.

MAYES, Renae; HINES, Erik; BIBBS, Deidra; RODMAN, Jennifer. Couselors and psychologists mentoring gifted black males with disabilities to foster college and career readiness, Gifted Child Today, v.42, n.3, p. 157-164, 2019. Disponível em: $\underline{\text { https://sci- }}$ hub.se/https://doi.org/10.1177\%2F1076217519843150. Acesso em: 15 maio 2021.

MAYES, Renae. College and career readiness groups for gifted black students with disabilities, The Journal for Specialists in Group Work, v.45, n. 3, p. 200-212, 2020. Disponível em: https://scihub.se/https://doi.org/10.1080/01933922.2020.1789790. Acesso em: 17 jun. 2021.

MOHAMMED, Amra. Twice-exceptionality in the Kingdom of Saudi Arabia: policy recommendations for advances in Special Education, International Journal Of Special Education, v. 33, n. 2, p. 397-415, 2018. Disponível em: https://files.eric.ed.gov/fulltext/EJ1185585.pdf. Acesso em: 15 maio 2021.

NEIHART, Maureen. Identifying and providing services to twice exceptional children. In: PFEIFER, Steven (Ed.). Handbook of giftedness in children: psycho-educational theory, research, and best practices.USA: Springer, 2008, p. 115-137.

OWENS, Charissa Owens; FORD, Donna; LISBON, April; OWENS, Michael. Shifting paradigms to better serve twice-exceptional african-american learners, Behavioral Disorders, v. 41, n. 4, p. 196-208, 2016. Disponível em: https://sci-hub.se/https://doi.org/10.17988\%2Fbedi-41-04-196-208.1. Acesso em: 20 maio 2021.

PARK, Soeun; FOLEY-NICPON, Megan; BOLENBAUGH, Mallory; CHOATE, Alyssa. "Nothing fits exactly": experiences of Asian American parents of twice-exceptional children, Gifted Child Quarterly, p. 1-14, 2018. Disponível em: https://sci-hub.se/https://doi.org/10.1177\%2F0016986218758442. Acesso em: 16 jun. 2021.

RANGNI, Rosemeire; COSTA, Maria Piedade. Altas Habilidades/superdotação e deficiência: reflexões sobre o duplo estigma, Educar em Revista, 53, 187-199, 2014. Disponível em: https://doi.org/10.1590/0104-4060.33859. Acesso em: 10 jun. 2021.

REIS, Sally; BAUM, Susan; BURKE, Edith. An Operational Definition of Twice- Exceptional Learners: Implications and Applications, Gifted Child Quarterly, v. 58, n. 3, 2014, p. 217-230. Disponível em: http://journals.sagepub.com.ez31.periodicos.capes.gov.br/doi/pdf/10.1177/0016986214534976.

Acesso em: 15 abr. 2018.

REIS, Sally; RENZULLI, Sara. Parenting for strenghts: embracing the challeges of raising children identified as twice exceptional, Gifted Education International, p. 1-13, 2020. Disponível em: https://scihub.se/https://doi.org/10.1177\%2F0261429420934435. Acesso em: 16 jun. 2021.

RENZULLI, Sara; GELBAR, Nicholas. Leadership roles for school counselors in identifying and supporting twice-excepctional (2E) students, Professional School Counseling, v. 23, n. 1, p. 1-11, 2020. Disponível em: https://sci-hub.se/https://doi.org/10.1177\%2F2156759X20940636. Acesso em: 15 maio 2021. 
RITCHOTTE, Jennifer; ZAGLAWAN, Hasan. Coaching parentes to use higher level questioning with their twice-exceptional children, Gifted Child Quarterly, p.1-16, 2019. Disponível em: https://scihub.se/https://doi.org/10.1177\%2F0016986218817042. Acesso em: 17 jun. 2021.

LIN, Chin-Lan; FOLEY-NICPON, Megan. Integrating creativity into career interventions for twice exceptional students in the United States: a review of recent literature, Gifted and Talented International, Disponível em: https://sci-hub.se/https://doi.org/10.1080/15332276.2019.1704667. Acesso em: 17 jun. 2021.

SCORSOLINI-COMIN, Fábio; SANTOS, Manoel. Psicologia Positiva e os Instrumentos de Avaliação no Contexto Brasileiro, Psicologia: Reflexão e Crítica, v. 23, n. 3, p. 440-448, 2010. Disponível em: https://www.scielo.br/j/prc/a/QLdLwrhpwV9WJXrcPCTPV9v/abstract/?lang=pt. Acesso em: 01 jul. 2021.

SEVERINO, Antônio. Metodologia do trabalho cientificio. 22.ed. São Paulo: Cortez, 2002.

SOUZA, Marcela; SILVA, Michelly; CARVALHO, Rachel. Revisão integrativa: o que é e como fazer. Einsten, São Paulo, v. 8, n. 1, p. 102-106, 2010. Disponível em: https://www.scielo.br/j/eins/a/ZQTBkVJZqcWrT'T34cXLjtBx/?format=pdf\&lang=pt. Acesso em: 20 maio 2021.

STETLER, Cheryl; MORSI, Deborah; RUCKI, Sheila Brought; CORRIGAN, Barbara; FITZGERALD, Jan; GIULIANO, Karen; HAVENER, Patricia; SHERIDAN, Ann. Utilization-focused integrative reviews in a nursing service, Applied Nursing Research, v. 11, n. 4, p. 195-206, 1998. Disponível em: https://www.researchgate.net/publication/13434441 Utilization-

focused integrative reviews in a nursing service. Acesso em: 14 mar. 2021.

TRAIL, Beverly. Twice-exceptional gifted children: understanding, teaching and counseling gifted students. USA: Prufrock Academic Press, 2011.

WEBB, James; AMEND, Edward; BELJAN, Paul; WEBB, Nadia; KUZUJANAKIS, Marianne; OLENCHAK, Richard; GOERSS, Jean. Misdiagnosis and dual diagnoses of gifted children and adults: ADHD, Bipolar, OCD, Asperger's, Depression, and other disorders. 2. ed. Tucson, AZ: Great Potential Press, 2016.

WHITTEMORE, Robin; KNAFL, Kathleen. The integrative review: updated methodology, Journal of Advanced Nursing, v. 52, n. 5, p. 546-553, 2005. Disponível em: https: / / citeseerx.ist.psu.edu/viewdoc/download?doi=10.1.1.465.9393\&rep=rep1\&type=pdf. $\quad$ Acesso em: 15 maio 2021.

WU, I-Chen; LO, Owen; TSAI, Kuei-Fang. Learning experiences of highly able learners with ASD: using a success case method, Journal for the Education of the Gifted, v. 42, n. 3, p.216-242, 2019. Disponível em: https://sci-hub.se/https://doi.org/10.1177\%2F0162353219855681. Acesso em: 15 maio 2021. 